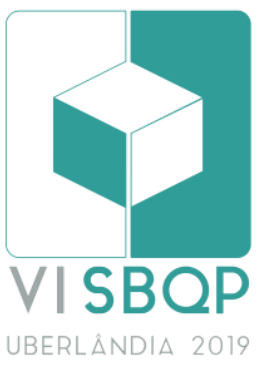

\title{
ANÁLISE ACÚSTICA DE PRAÇAS PÚBLICAS NA CIDADE DE JUIZ DE FORA
}

\author{
SOUZA, Thaísa \\ Universidade Federal de Juiz de Fora, thaisa.souza@arquitetura.ufjf.br \\ SENRA, Silvia \\ Universidade Federal de Juiz de Fora, sil.senra@gmail.com \\ CASSANI, Maria \\ Universidade Federal de Juiz de Fora, maria.cassani.5@gmail.com \\ BARBOSA, Sabrina \\ Universidade do Estado do Rio de Janeiro, sabrina.barbosa@verj.br \\ ALBERTO, Klaus \\ Universidade Federal de Juiz de Fora, klaus.alberto@ufjf.edu.br
}

\begin{abstract}
RESUMO
Com o crescimento das cidades e da complexidade da malha urbana, a polvição sonora tem se tornado um mal crescente, prejudicando a saúde pública e ambiental. Neste contexto, as praças podem atuar como ambientes benéficos para a população, ajudando no controle do ruído urbano. Essa pesquisa tem como objetivo avaliar o nível de ruído das praças públicas de Juiz de Fora - MG, contribuindo para a caracterização da polvição sonora da cidade e aferindo, de maneira indireta, se estas contribuem para o bem-estar dos usuários. Para isso, foram realizadas medições sonoras in loco no período da tarde em dias de semana em 87 praças. Os valores obtidos foram comparados aos estabelecidos pela NBR 10.151/2003, pela Organização Mundial da Saúde (OMS) e por resultados de outras pesquisas realizadas em localizações distintas. A partir dos dados coletados, percebeu-se que a maioria das praças possui níveis de ruído superiores aos sugeridos pelas referências citadas. Esse trabalho tem como contribuição o levantamento dos valores de nível de pressão sonora nas praças, demonstrando ao poder público pontos críticos para que sejam iniciadas ações corretivas.
\end{abstract}

Palavras-chave: Polvição sonora, Ruído, Praças.

\begin{abstract}
With the growth of cities and the complexity of the urban mesh, noise pollution has become a growing harm, damaging public and environmental health. In this context, squares can act as beneficial environments to the population, helping in noise control. Therefore, this research aims to verify the noise level of the public squares in Juiz de Fora-MG, contributing to the characterization of the noise pollution of the city and assessing, indirectly, if they contribute to the wellbeing of users. To that, visits in loco were made and sound measurements were performed at afternoons of weekdays in 87 squares. The values obtained were compared with those established by the NBR 10.151/2003, the World Health Organization (WHO) and results of other surveys conducted at different locations. From the data collected, it was noticed that most of the squares have higher noise levels than those suggested by the references. The contribution of this research is the gathering of the values of sound pressure level in squares, demonstrating critical points for the public authorities to initiate corrective actions.
\end{abstract}

Keywords: Sound pollution, Noise, Squares.

SOUZA, T.; SENRA, S; CASSANI, M; BARBOSA, S; ALBERTO, K. Análise acústica de praças públicas na cidade de Juiz de Fora. In: SIMPÓSIO BRASILEIRO DE QUALIDADE DO PROJETO NO AMBIENTE CONSTRUÍDO, 6., 2019, Uberlândia. Anais... Uberlândia: PPGAU/FAUeD/UFU, 2019. p. 882-891. DOI https://doi.org/10.14393/sbqp19082. 


\section{INTRODUÇÃO}

O ruído, definido como um som indesejável, gera diversos efeitos negativos na saúde humana, como perda de audição e estresse (BISTAFA, 2011), e é considerado um dos principais problemas ambientais no mundo, atrás somente da poluição do ar (WHO, 2018). A Organização Mundial de Saúde (OMS) (WHO, 2011) afirma que o ruído não deve ser tratado apenas como um incômodo, mas como um tema para saúde pública e ambiental. Pode-se dizer que desde o século XVIII, com a Revolução Industrial, esse problema vem se agravando (MURGEL, 2007), tendo em vista o crescimento da urbanização, da economia e do aumento do transporte viário, que contribuem para a expansão dessa poluição (WHO Europe, 2011). Contudo, poucas são as iniciativas de mitigação dos efeitos negativos tanto por parte do poder público quanto do privado. Estudos apresentados pela OMS (2018) mostram que pelo menos 1 milhão de anos de vidas são perdidas na Europa Ocidental devido ao ruído de diversos tipos de tráfego (WHO, 2018).

Neste contexto, as praças públicas, além de trazerem grandes benefícios à saúde mental e física da população (MCCORMACK et al., 2010), ajudam no ecossistema das cidades e no controle de ruído. Entretanto, como estão presentes nos centros urbanos, as praças acabam recebendo alto ruído gerado principalmente pelo fluxo automobilístico, o que pode diminuir sua eficácia como área de lazer e, consequentemente, reduzir a presença de pessoas no local (CALLEJA et al., 2017). Além disso, elas configuram-se como geradores de ruído a partir dos próprios usuários, seja utilizando o playground, realizando atividades físicas ou conversando em grupos (JEON; HONG, 2015).

Considerando os benefícios de áreas verdes para o meio urbano e para a saúde humana, assim como a importância de sua preservação, percebe-se que ainda são necessários novos estudos sobre o tema, em diferentes contextos geográficos, para ampliar a base de dados. Esses estudos podem ser feitos por meio de medições acústicas, com o uso de equipamentos adequados e devidamente calibrados, que permitem avaliar se o ruído existente em um local está em conformidade com as normas específicas e qual é o impacto gerado no ambiente e na comunidade que o cerca (DEPARTAMENT OF ENVIRONMENT MALAYSIA, 2007).

Esse estudo, que é parte de uma dissertação de mestrado do Programa de Pós-Graduação em Ambiente Construído da Universidade Federal de Juiz de Fora, tem como objetivo avaliar a polvição sonora de 87 praças públicas de Juiz de Fora - MG, o que corresponde a $78 \%$ do total. Dessa forma, este trabalho contribui para o levantamento dos valores de nível de pressão sonora nas praças, demonstrando ao poder público pontos críticos para que sejam iniciadas ações corretivas.

\section{REVISÃO BIBLIOGRÁFICA}

O diagnóstico de ruídos e seus impactos nos usuários são temas de diversas pesquisas que abordam os espaços livres públicos. Zhang et al. (2018) estudaram uma praça na China com o intuito de descobrir o efeito de quatro dimensões (relaxamento, comunicação, espacialidade e dinâmica) da paisagem sonora nos usuários. Os autores perceberam que a dominância das fontes naturais daquele local resultou em um efeito significativo nas quatro dimensões, sendo que o relaxamento dos usuários acontecia de forma mais 
evidente quando ouviam, predominantemente, sons naturais do ambiente do que sons mecânicos, como trânsito. Isso pode ter acontecido devido ao som mecânico ser algo aleatório e descontínuo, segundo os autores.

Swain e Goswami (2018) avaliaram 3 parques urbanos de duas cidades na Índia que possuíam grande densidade demográfica ao seu redor, por meio de medições in loco e aplicação de questionário. Os níveis de pressão sonora desses parques ultrapassaram $50 \mathrm{~dB}$ (A) (limite máximo considerado pelos autores), sendo o ruído de tráfego o mais percebido pelos usuários. Por outro lado, Jeon e Hong (2015) mostraram que os parques estudados em Madri se encontram dentro dos valores médios de ruídos do país (55-58dB (A)) e que, apesar de ultrapassar algumas recomendações europeias (45-55dB (A)), esse nível de pressão sonora é registrado em várias praças na Itália, Brasil e China e ainda está de acordo com o estabelecido pela Lei de ruído da Espanha (65 $d B(A))$.

No Brasil, Zannin et al. (2006) avaliaram 6 praças em Curitiba-PR utilizando, como referência, limites da legislação municipal $(55 \mathrm{~dB}(\mathrm{~A}))$, assim como recomendações europeias de Roma (50dB (A)), Itália, e Alemanha (55dB (A)). Metade dos espaços estudados possuía alto nível de ruído causado pelo tráfego de veículos, falta de planejamento urbano e falta de abordagem pela legislação municipal. Os outros três espaços, no entanto, apresentaram nível de ruído dentro do permitido pelas normas, devido ao seu afastamento da malha urbana. Na mesma cidade, Szeremeta e Zannin (2015) aplicaram o estudo em outros 3 parques que são cercados por vias rodoviárias e 1 que se situa em uma região mais tranquila. Foram realizadas medições e mapeamento de ruído nos 4 locais, além da aplicação de questionário aos praticantes de atividade física que estavam presentes no momento da medição. Os resultados, comparados com o limite municipal estabelecido de $55 \mathrm{~dB}(\mathrm{~A})$, mostraram que apenas 1 parque estava em acordo com o máximo estipulado. Porém, mesmo assim, os usuários avaliaram positivamente a qualidade desses ambientes. Para os autores, isso pode ter ocorrido por já estarem acostumados ao barulho em seu dia-a-dia, além de que podem ter sido induzidos à resposta por compararem esses locais com espaços fechados de seus cotidianos.

Em Belo Horizonte, Hirashima e Assis (2016) também analisaram 2 praças cercadas pelo tráfego rodoviário, considerando a opinião de voluntários. Em uma delas, os níveis sonoros atingiram um pico de $95 \mathrm{~dB}(\mathrm{~A})$ e os usuários se queixaram de barulho alto. Na outra, apesar de registrarem níveis de pressão sonora de $69 \mathrm{~dB}(\mathrm{~A})$, também muito acima do normatizado, os usuários não relataram o mesmo desconforto talvez pelo fato dessa praça ser mais convidativa.

\section{METODOLOGIA}

A metodologia usada neste estudo foi dividida em 4 partes principais:

1. Mapeamento e caracterização das praças de Juiz de Fora.

2. Definição do período de realização de medições.

3. Realização das medições sonoras in loco.

4. Avaliação dos dados e comparação com referências normativas. 


\subsection{Mapeamento e caracterização das praças de Juiz de Fora}

Inicialmente foi realizado um levantamento de todas as praças de Juiz de Fora (Figura 1). A prefeitura do município considera 169 Espaços Livres Públicos (ELPS) como praças. Entretanto, apenas 104 poderiam de fato ser denominados como praças, já que alguns espaços eram, por exemplo, terrenos baldios, canteiros ou trevos. Além disso, outros locais foram descartados por serem considerados como inseguros ou localizados em distritos mais afastados. Assim, para o levantamento foram consideradas 87 praças públicas da cidade.

As praças avaliadas encontram-se distribuídas em todas as regiões urbanas de Juiz de Fora garantindo variedade amostral. Elas possuem áreas para prática de esportes, exercícios e atividades físicas, contando também com quiosques de alimentação, bancas de revista, playgrounds e outros equipamentos. A presença destes elementos varia em qualidade e quantidade, uma vez que certas praças apresentam apenas um desses aparelhos, enquanto outras apresentam mais. Essas condições, atreladas à localização, propiciam a presença e circulação de pessoas, além do fluxo de veículos ao redor, o que contribui para o aumento do nível de ruído. Das praças analisadas, apenas 5 encontram-se no bairro Centro (6\% do total); as demais também estão inseridas em meio à malha urbana, em diferentes bairros, distribuídas por toda a área da cidade.

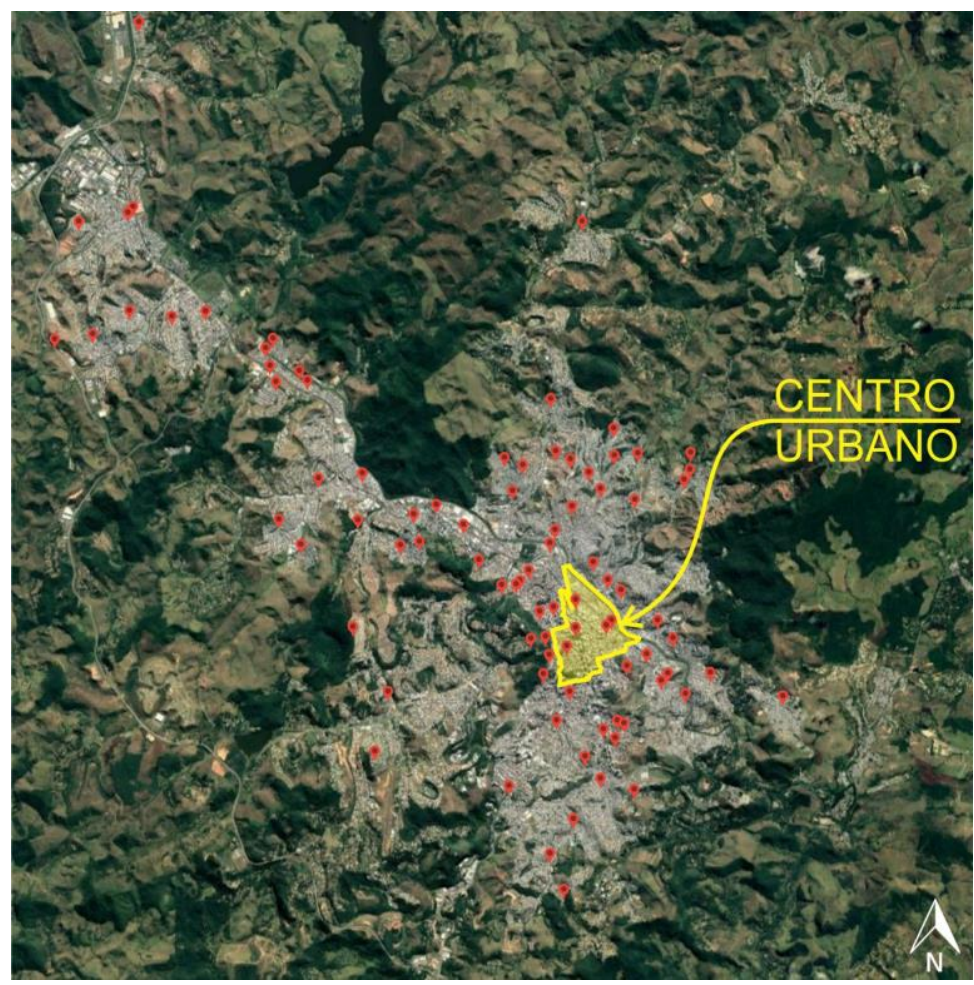

Figura 1 - Município de Juiz de Fora - MG e localização das praças avaliadas Fonte: Autores (2019)

\subsection{Definição do período de realização das medições}

Estabeleceu-se que o horário mais adequado para executar medições seria no turno da tarde, entre $14 \mathrm{~h}$ e $18 \mathrm{~h}$, pois é o momento que apresenta maior quantidade e diversidade de pessoas nesses locais. As medições foram realizadas em dias típicos de semana, durante o período escolar. As praças 
foram visitadas durante o período de aproximadamente dois meses. As medições foram realizadas em dias sem chuva (com sol ou nublado) e com pouco ou nenhum vento de forma a não interferir nos dados aferidos. Além disso, consideraram-se os dias com boas condições climáticas (média de temperatura de $24^{\circ} \mathrm{C}$ ). Em cada praça, os valores medidos foram anotados no protocolo de visita desenvolvido, que também contém o horário da medição e o endereço da mesma, assim como a temperatura local, a condição climática no momento, a data e os horários inicial e final da visita.

\subsection{Realização das medições sonoras in loco}

O nível de ruído foi medido de acordo com as recomendações da norma NBR 10.151/2003. Foi utilizado um decibelímetro digital portátil Mod. DEC-460 da marca Instrutherm, ponderado em "A", modo "Fast", além de um aplicativo para medição da pressão sonora disponibilizado para smartphones. Esse último foi testado e calibrado previamente. O aparelho de medição foi fixado a uma distância de, no mínimo, $1,2 \mathrm{~m}$ do piso e $2 \mathrm{~m}$ de qualquer superfície refletora. Em campo, foi feito um teste comparativo entre o aplicativo e o decibelímetro durante três minutos e o resultado obtido foi similar, o que validou a utilização do smartphone. Quanto ao tempo de medição, a NBR 10.151 não determina um tempo mínimo necessário, mas afirma que o valor deve ser o suficiente para caracterizar o ruído local, considerando o mínimo de 30 segundos. A ferramenta ICAM (ITDP, 2018), também utilizada como referência para essa pesquisa, além de admitir $O$ uso de aplicativos simuladores, considera necessária a medição de, no mínimo, 20 segundos consecutivos. Dessa forma, o período de tempo adotado para as medições desse estudo foi de 1 minuto. Essa mesma ferramenta avalia segmentos de calçada e, para isso, escolhe o ponto mais crítico do mesmo e admite o uso deste resultado para análise de todo o segmento. De forma análoga, considerou-se o centro da praça como ponto crítico, pois se encontra equidistante de todas as áreas e também é, muitas vezes, o local no qual as pessoas se concentram.

O protocolo de visita utilizado para as medições foi desenvolvido com base em referências de estudos semelhantes como Analytic Audit Tool and Checklist Audit Tool (BROWNSON et al, 2004), BRAT-DO: BRAT-Direct Observation, (BENDIMO-RUNG, 2005) e CPAT: Community Park Audit Tool (KACZYNSKI et al., 2012). Foram levantados os usos do solo do perímetro de cada praça (residencial, comercial, serviço, institucional ou lotes vazios) e posteriormente, os dados foram organizados e tratados em planilhas de forma a identificar as porcentagens de cada uso e averiguar qual deles era predominante.

\subsection{Avaliação dos dados e comparação com referências normativas}

Nesse estudo, para a avaliação do nível de ruído, foram levadas em consideração a norma brasileira NBR 10.151/2003 (Acústica - Avaliação do ruído em áreas habitadas, visando o conforto da comunidade Procedimento) e a recomendação da OMS (1999). A NBR 10.151 estabelece o padrão exigido à aceitabilidade do ruído em ambientes externos (Tabela 1). 0 uso térreo dos lotes do entorno das praças dessa pesquisa foi avaliado e classificado, segundo a norma, como "predominantemente residencial". Assim, adotou-se o valor do Nível de Critério de Avaliação (NCA) como 55dB (A). 
Tabela 1 - Nível de Critério de Avaliação NCA para ambientes externos em db (A)

\begin{tabular}{|c|c|c|}
\hline Tipos de áreas & Diurno & Noturno \\
\hline Áreas de sítios e fazendas & 40 & 35 \\
\hline $\begin{array}{l}\text { Área estritamente residencial urbana ou de hospitais ou de } \\
\text { escolas }\end{array}$ & 50 & 45 \\
\hline Área mista, predominantemente residencial & 55 & 50 \\
\hline Área mista, com vocação comercial e administrativa & 60 & 55 \\
\hline Área mista, com vocação recreacional & 65 & 55 \\
\hline Área predominantemente industrial & 70 & 60 \\
\hline
\end{tabular}

Fonte: ABNT, NBR 10151 (2003)

A OMS, por outro lado, recomenda dois níveis de ruído para ambientes considerados como áreas de estar externas. O primeiro limite (55dB (A)) é considerado como efeito crítico para a saúde, gerando um incômodo sério e o segundo (50dB (A)), um incômodo moderado, conforme demonstrado na Tabela 2. Além disso, ela estabelece que o tempo de exposição no qual as pessoas se submetem a esse ruído deve ser de, no máximo, 16 horas. Portanto, além do limite estabelecido pela NBR 10.151, também foi adotado o limite mais restritivo da OMS para área de estar externa $(50 \mathrm{~dB}(\mathrm{~A}))$ de forma a evitar efeitos negativos à saúde humana.

Tabela 2 - Orientações para ruído na comunidade segundo OMS, 1999

\begin{tabular}{|c|c|c|c|c|}
\hline $\begin{array}{c}\text { Ambiente } \\
\text { específico }\end{array}$ & $\begin{array}{c}\text { Efeito (s) crítico (s) para a } \\
\text { saúde }\end{array}$ & dBA Leq & $\begin{array}{c}\text { Período de tempo } \\
\text { (horas) }\end{array}$ & $\begin{array}{c}\text { LA } \\
\text { máximo }\end{array}$ \\
\hline \multirow{2}{*}{$\begin{array}{c}\text { Área de estar } \\
\text { externa }\end{array}$} & Incômodo sério, dia e noite & 55 & 16 & - \\
\cline { 2 - 5 } & $\begin{array}{c}\text { Incômodo moderado, dia e } \\
\text { noite }\end{array}$ & 50 & 16 & - \\
\hline
\end{tabular}

Fonte: OMS (1999), adaptado pelos autores

\section{RESULTADOS E DISCUSSÃO}

A média do ruído nas 87 praças avaliadas de Juiz de Fora foi de 58 dB (A), o que está acima dos limites definidos pelas duas referências adotadas nesse artigo (Figura 2). A praça com nível sonoro mais alto foi a Alfredo Lage, apresentando $82 \mathrm{~dB}$ (A). Esse valor pode ser explicado devido a sua proximidade com a Avenida Brasil, importante via da cidade, onde ocorre um fluxo intenso de veículos. Já a praça Carlos Rutier apresentou 36 dB (A), o nível sonoro mais baixo encontrado. Essa ocorrência pode ser justificada devido à sua localização, uma vez que se situa no bairro Granbery, majoritariamente residencial e não possui vias de fluxo intenso nas redondezas. Por outro lado, $62 \%$ das praças ultrapassam o limite de $55 \mathrm{~dB}(\mathrm{~A})$, resultado similar aos valores encontrados por Zannin (2006). A média do ruído nas praças da cidade (58 dB (A)) foi similar aos valores apontados por Jeon e Hong (2015) em Madri (55$58 \mathrm{~dB}(\mathrm{~A}))$.

Das praças analisadas, 33 (38\% do total) atendem ao valor definido pela NBR 10.151. Entretanto, considerando o limite recomendado pela OMS, esse percentual reduz para apenas $18 \%$ (16 praças). Assim, 71 praças ( $82 \%$ do total) não atendem simultaneamente aos dois critérios indicados e apenas 16 praças avaliadas encontram-se adequadas em relação ao nível de pressão 
sonora. Esses casos podem ser explicados pelo uso do solo do entorno ser majoritariamente residencial e pelo fato de se encontrarem afastadas de vias de grande fluxo (exceto a Praça Jarbas de Lery Santos), o que pode explicar a intensidade sonora dentro dos limites recomendados.
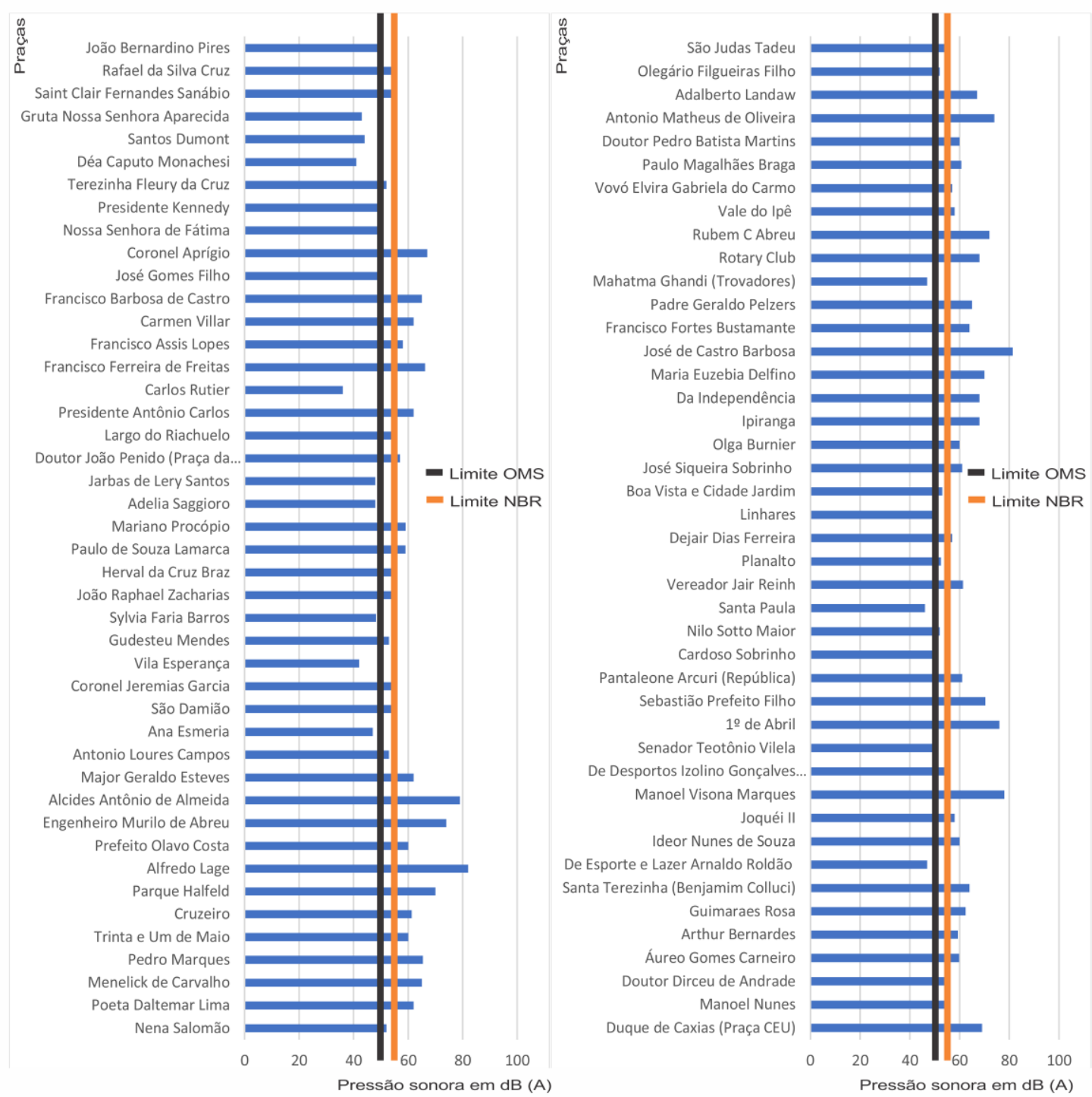

Figura 2 - Resultado das medições por praça -

Fonte: Autores (2019)

Dentre as praças avaliadas, 8 (9\% do total) registraram níveis extremamente elevados de ruído (acima de 70dB (A)). Morfologicamente, encontram-se localizadas dentro da malha urbana ou próximas ao centro da cidade, sendo em alguns casos cercadas por vias de grande fluxo. Uma vez que a aferição foi feita estrategicamente no período da tarde, o fluxo de pedestres no interior e ao redor das praças também pode ter sido responsável por esse alto nível de ruído, pois algumas praças são frequentadas diariamente nos horários de maior fluxo.

Percebeu-se que não há expressiva diferença do nível sonoro entre praças com ou sem áreas verdes. Os casos com nível de pressão sonora dentro dos limites considerados possuem média de $38 \%$ de áreas verdes. Por outro lado, nas praças com valores superiores aos indicados pelas normas, as áreas verdes 
representam $40 \%$ de suas áreas, em média. Esse resultado contraria a hipótese inicial de que a qualidade sonora das praças está relacionada às suas áreas verdes.

As praças adequadas às normas possuem áreas maiores do que as praças consideradas inadequadas. Enquanto as primeiras possuem uma média de área de pouco mais de $5.500 \mathrm{~m}^{2}$, as pertencentes à segunda condição têm $2.900 \mathrm{~m}^{2}$ de área média. Como as medições foram realizadas no centro da praça, esses valores podem indicar a expressiva influência do ruído gerado no entorno das praças. Contudo, para maior precisão dos resultados sobre a condição sonora das praças, será necessário um novo estudo que considere pontos de medição não só no centro, mas também nas extremidades das praças de forma a considerar a heterogeneidade sonora do espaço.

É necessário observar, contudo, que os limites estabelecidos pelas normas e utilizados como referência neste artigo podem estar desatualizados para a atual realidade urbana, visto que as cidades apresentam um desenvolvimento constante e consequentemente, aumento da pressão sonora. Ainda assim, é preciso que as avaliações considerem os padrões estabelecidos, uma vez que os valores obtidos estão acima dos aceitáveis e podem ser prejudiciais à saúde humana.

\section{CONCLUSÕES}

Este estudo avaliou o nível de ruído de $78 \%$ do total de áreas externas públicas consideradas praças na cidade de Juiz de Fora - MG, totalizando 87 praças. A avaliação in loco se deu através de medições sonoras por meio de decibelímetros e aplicativos de aferição do nível sonoro para smartphones. Os dados foram comparados a valores limites estabelecidos pela NBR 10.151 (2003) e pela OMS (1999). Vale ressaltar que a utilização de smartphones é uma limitação do estudo, pois apesar de o equipamento ter apresentado resultados semelhantes ao decibelímetro no período em que foi testado, esta não é uma ferramenta com acurácia para a análise.

Das praças avaliadas, 71 casos não atendem aos critérios estabelecidos pelas normas utilizadas como referência e, portanto, apenas 16 praças avaliadas encontram-se adequadas em relação ao nível de pressão sonora. Essas praças encontram-se em áreas predominantemente residenciais e, em sua maioria (93\% das praças consideradas adequadas), distantes de áreas de fluxo intenso de automóveis. Os resultados indicaram que $82 \%$ dos casos estão sujeitos ao alto nível de ruído, fazendo com que, muitas vezes não consiga transmitir bem-estar como área de lazer.

A avaliação permitiu entender a realidade da polvição sonora das praças de Juiz de Fora. Os dados levantados permitem ao poder público avaliar e identificar pontos mais ou menos críticos para a tomada de ações corretivas. Como soluções para o conforto acústico de tais espaços sugerem-se distanciar os Espaços Livres Públicos de áreas com intenso tráfico de veículos, além da inserção de reguladores de velocidade e proibição do uso de buzina. 


\section{AGRADECIMENTOS}

Os autores agradecem o apoio do Conselho Nacional de Desenvolvimento Científico e Tecnológico (CNPq) e da Coordenação de Aperfeiçoamento de Pessoal de Nível Superior (CAPES).

\section{REFERÊNCIAS}

ASSOCIAÇÃO BRASILEIRA DE NORMAS TÉCNICAS (ABNT). NBR 10.151: Acústica Avaliação do ruído em áreas habitadas, visando o conforto da comunidade Procedimento. Rio de Janeiro, 2003.

BENDIMO-RUNG, A. L. et al. Development of a Direct Observation Instrument to Measure Environmental Characteristics of Parks for Physical Activity. Journal of Physical Activity and Health, 3, Suppl 1, S176-S189. 2006.

BISTAFA, S. R. Acústica aplicada ao controle do ruído. 2 ed. São Paulo: Blucher, 2011.

BROWNSON, R. C.; HOEHNER, C. M.; BRENNAN, L. K.; COOK, R. A.; ELLIOTT, M. B.; MCMULLEN, K. M. Reliability of 2 instruments for auditing the environment for physical activity. Journal of Physical Activity and Health, v. 1, p. 189-207, 2004.

CALLEJA, A.; DÍAZ-BALTEIRO, L.; MERCHAN, C.; SOLIÑO, M. Acoustic and economic valuation of soundscape: An application to the 'Retiro' Urban Forest Park. Urban Forestry \& Urban Greening, v. 27, p. 272-278, 2017.

DEPARTAMENT OF ENVIRONMENT MALAYSIA. The planning guidelines for environmental noise limits and control. 2 ed. Malásia: Noise Data Section, Air Division, Departament of Environment Malaysia, 2007. Disponível em: <https://www.doe.gov.my/portalv1/en/info-umum/the-planning-guidelines-forenvironmental-noise-limits-and-control/272>. Acesso em: 21 jan. 2019.

HIRASHIMA, S. Q. S.; ASSIS, E. S. Percepção sonora e conforto acústico em espaços urbanos do município de Belo Horizonte, MG. Ambiente Construído, Porto Alegre, v. 17, n. 1, p. 7-22, 2017.

ITDP Brasil. Índice de Caminhabilidade Versão 2.0 - Ferramenta (2018). Disponível em: <http://itdpbrasil.org.br/wpcontent/uploads/2018/01/ITDP_TA_CAMINHABILIDADE_V2_ABRIL_2018.pdf>. Acesso em: 19 jan. 2019.

JEON, J. Y.; HONG, J. Y. Classification of urban park soundscapes through perceptions of the acoustical environments. Landscape and Urban Planning, $v$. 141, p. $100-111,2015$.

KACZYNSKI, A. T. et al. Development and Testing of a Community Stakeholder Park Audit Tool. American Journal of Preventive Medicine, 2012.

MCCORMACK, G. R.; ROCK, M.; TOOHEY, A. M.; HIGNELL, D. Characteristics of urban parks associated with park use and physical activity: A review of qualitative research. Health \& Place, v. 16, p. 712-726, 2010.

MURGEL, E. Fundamentos de Acústica Ambiental. São Paulo: Senac, 2017.

SWAIN, B. K.; GOSWAMI, S. Soundscapes of Urban Parks in and around Bhubaneswar and Puri, Odisha, India: A Comparative Study. Pollution, v. 4(1), p. 93-101, 2018. 
SZEREMETA, B.; ZANNIN, P. H. T. A percepção dos praticantes de atividade física sobre a qualidade ambiental sonora dos parques públicos de Curitiba-Paraná. RAEGA, v.33, p.07-43, 2015.

WHO (2011). European Centre for Environment and Health. Burden of disease from environmental noise quantification of healthy life years lost in Europe 2011. Copenhagen: World Health Organization Regional Office for Europe. Disponível em: <https://www.who.int/quantifying_ehimpacts/publications/e94888/en/>. Acesso em: 06 fev. 2019.

WHO (1999). European Centre for Environment and Health. Guidelines for Community Noise. Geneva: World Health Organization Regional Office for Europe. Disponível em: <http://www.who.int/iris/handle/10665/66217>. Acesso em: 09 fev. 2019.

ZANNIN, P. H. T.; FERREIRA, A. M. C.; SZEREMETTA, B. Evaluation of noise pollution in urban parks. Environmental Monitoring and Assessment, v. 118, p. 423-433, 2006.

ZHANG, X.; BA, M.; KANG, J.; MENG, Q. Effect of soundscape dimensions on acoustic comfort in urban open public spaces. Applied Acoustics, v. 133, p. 7381, 2018. 